\title{
PERBANDINGAN BIT ERROR RATE KODE REED-SOLOMON DENGAN KODE BOSE-CHAUDHURI-HOCQUENGHEM MENGGUNAKAN MODULASI 32-FSK
}

\author{
Eva Yovita Dwi Utami*, Liang Arta Saelau dan Andreas A. Febrianto \\ Program Studi Teknik Elektro, Universitas Kristen Satya Wacana \\ *Corresponding author, e-mail : eva.utami@staff.uksw.edu
}

\begin{abstract}
Abstrak - Kode Reed-Solomon (RS) dan kode Bose-Chaudhuri-Hocquenghem (BCH) merupakan kode pengoreksi error yang termasuk dalam jenis kode blok siklis. Kode pengoreksi error diperlukan pada sistem komunikasi untuk memperkecil error pada informasi yang dikirimkan. Dalam makalah ini, disajikan hasil penelitian kinerja BER sistem komunikasi yang menggunakan kode RS, kode $\mathrm{BCH}$, dan sistem yang tidak menggunakan kode RS dan kode $\mathrm{BCH}$, menggunakan modulasi 32-FSK pada kanal Additive White Gaussian Noise (AWGN), Rayleigh dan Rician. Kemampuan memperkecil error diukur menggunakan nilai Bit Error Rate (BER) yang dihasilkan. Hasil penelitian menunjukkan bahwa kode RS seiring dengan penambahan nilai SNR, menurunkan nilai $B E R$ yang lebih curam bila dibandingkan sistem dengan kode $\mathrm{BCH}$. Sedangkan kode $\mathrm{BCH}$ memberikan keunggulan saat SNR bernilai kecil, memiliki BER lebih baik daripada sistem dengan kode RS.
\end{abstract}

Kata Kunci : BCH, Reed Solomon, BER

\begin{abstract}
Reed-Solomon (RS) Code and Bose-Chaudhuri-Hocquenghem (BCH) code are cyclic block codes class of error-correting code.Error correcting code is required in communicaton system to reduce error of transmitted information from transmitter to receiver. In this paper, we present the investigation result of BER performance of communication system using RS code, $\mathrm{BCH}$ code and the system without error-correcting code. The simulation of the system is built using Matlab. The simulated communication system also use 32-Frequency Shift Keying modulation, and the encoded information which are investigated will propagate through AWGN, Rician and Rayleigh channel. Code performances is measured using bit error rate (BER) values. The results show that RS code performance in higher SNR, decrease BER values sharper than $\mathrm{BCH}$ code. But $\mathrm{BCH}$ code gives superior performance in lower SNR values.
\end{abstract}

Keywords : BCH, Reed Solomon, BER

Copyright $\odot 2016$ JNTE. All rights reserved

\section{PENDAhUluan}

Tujuan sistem komunikasi adalah membawa sinyal informasi dari suatu titik (yaitu pengirim atau transmitter) ke titik yang lainnya (yaitu penerima atau receiver) melalui kanal komunikasi. Informasi yang diterima diharapkan sama dengan yang dikirimkan. Namun selama proses transmisi, dapat terjadi distorsi pada informasi karena ketidaksempurnaan kanal. Selain itu adanya derau dan sinyal penginterferensi dari sumber lain akan menyebabkan informasi yang diterima tidak lagi seperti yang dikirimkan [1].

Dalam sistem komunikasi digital, sinyal informasi yang dikirimkan berupa bit atau simbol. Karena adanya efek gangguan, derau dan interferensi, bit atau simbol yang diterima menjadi tidak sama dengan yang dikirimkan atau telah mengalami error. Untuk mengatasinya, telah dikembangkan berbagai teknik errordetecting code yaitu teknik pengkodean untuk mendeteksi adanya error serta teknik errorcorrecting code yaitu teknik pengkodean untuk mengoreksi error. Pengkodean dilakukan dengan menambahkan bit atau simbol tambahan (redundancy) pada informasi yang akan dikirimkan pada proses transmisi, dan kemudian didekodekan dengan suatu algoritma tertentu pada receiver agar dapat dideteksi dan dikoreksi. Dengan teknik pengoreksi error, laju kesalahan bit atau bit error rate (BER) dapat diturunkan. Kode pengoreksi error terbagi atas 2 bagian, yaitu kode blok (block code) dan kode 
konvolusional (convolution code). Contoh kode pengoreksi error yang merupakan kode blok adalah kode Reed-Solomon (RS) dan kode BoseChaudhuri-Hocquenghem (BCH).

Kode RS dan BCH merupakan kode siklis yang unik karena proses pengoreksiannya dilakukan sekaligus untuk beberapa bit, sehingga kode RS dan BCH memiliki kecepatan komputasi yang lebih tinggi dibandingkan jenis pengoreksian error yang proses koreksinya dilakukan untuk tiap bit. Selain itu, kedua kode tersebut juga mempunyai tingkat akurasi yang tinggi.

Pada penelitian [2], kinerja BER kode RS dengan modulasi M-FSK diteliti pada kondisi kanal AWGN dengan variasi jumlah bit redundancy dan panjang kode. Penelitian [3] membahas kinerja BER kode RS pada kanal AWGN, Rayleigh dan Rician. Pada [4] dilaporkan kinerja kode $\mathrm{RS}$ dan $\mathrm{BCH}$ menggunakan modulasi BPSK dan QPSK pada kanal Rayleigh, dengan hasil kode RS memiliki kinerja BER lebih baik daripada kode $\mathrm{BCH}$.

Pada makalah ini dilaporkan hasil penelitian kinerja BER kode RS dan BCH menggunakan modulasi 32-FSK pada kanal AWGN, Rayleigh dan Rician. Penelitian dilakukan dengan cara memodelkan dan menyimulasikan sistem komunikasi digital yang terdiri dari encoderdecoder RS dan $\mathrm{BCH}$ dan modulatordemodulator 32-FSK. Simulasi dirancang menggunakan Matlab/Simulink.

\section{TINJAUAN PUSTAKA}

\subsection{Kode Reed-Solomon}

Kode RS merupakan pengkodean siklis nonbiner yang berguna sebagai "errorcorrecting code". Pengaplikasian kode ini banyak ditemukan pada $C D$ player dan dapat digunakan pada aplikasi deep space. Persamaan kode RS secara umum dinyatakan dalam $(n, k)$ dengan $n$ merupakan panjang kata kode dalam simbol dan $k$ merupakan panjang informasi yang akan dikodekan dalam simbol [5]. Dengan demikian kode yang ditambahkan sejumlah $n-k$.

Kelebihan kode Reed-Solomon dibandingkan kode pendeteksi atau kode pengoreksi yang lain adalah kode RS sangat efektif terhadap burst error dan kode RS memiliki kemampuan koreksi lebih banyak karena data diolah dalam simbol (non-binary code). Kode ini dapat memperbaiki hingga $t$ simbol error [5] yaitu

$$
t=\frac{n-k}{2}
$$

dengan $t$ merupakan jumlah simbol yang dapat diperbaiki dari error yang didapat. Misal kode RS $(n, k)=(255,247)$, maka $t=(255-247) / 2=4$ simbol.

\subsection{Kode Bose-Chaudhuri-Hocquenghem (BCH)}

Kode BCH merupakan salah satu kode siklis yang ditemukan pada tahun 1959 oleh Hocquenghem sebagai metode pengkodean siklis yang memiliki tingkat perbaikan kesalahan yang tinggi dengan pengkodean yang lebih spesifik. Selanjutnya pada tahun 1960 metode tersebut disempurnakan oleh Bose dan Chaudhuri. Persamaan kode BCH secara umum $(n, k)$ dengan $n$ merupakan panjang kata kode dalam bit dan $k$ merupakan panjang informasi yang akan dikodekan dalam bit [6].

Kemampuan memperbaiki kesalahan pada teknik BCH dinyatakan sebagai $t$ dalam bentuk persamaan [6]

$$
t \geq \frac{n-k}{m}
$$

dengan $t$ menunjukkan jumlah bit yang mampu diperbaiki.

\section{METODOLOGI}

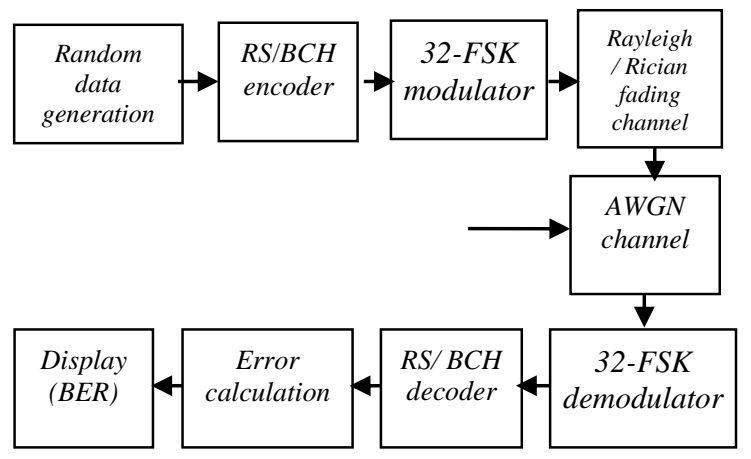

Gambar 1. Model sistem komunikasi dengan modulasi 32-FSK dan kode koreksi $\mathrm{RS} / \mathrm{BCH}$

Penelitian ini diawali dengan membuat simulasi menggunakan perangkat lunak Matlab, 
dengan data masukan pesan yang berasal dari data acak yang dihasilkan oleh program Matlab. Data masukan pesan berupa data biner acak sejumlah 832000 bit yang akan disusun dalam suatu matriks $832000 \times 1$. Sistem yang disimulasikan ditunjukkan pada Gambar 1.

Encoder RS menggunakan system object pada Matlab dengan syntax comm. RSEncoder. Data biner acak sejumlah 832000 bit tidak sekaligus diproses langsung, melainkan dibagi dalam frame. Setiap frame dikodekan per 16 bit masukan dengan kode $\operatorname{RS}(31,16)$ dan dikodekan per 26 bit masukan dengan kode $\operatorname{RS}(31,26)$. Untuk kode RS $(31,16)$ terdapat 2600 frame dan kode $\operatorname{RS}(31,26)$ terdapat 1600 frame.

Encoder $\mathrm{BCH}$ menggunakan system object pada Matlab dengan syntax comm.BCHEncoder. Data biner acak sejumlah 832000 bit tidak sekaligus diproses langsung, tetapi dibagi dalam frame. Setiap frame dikodekan per 16 bit masukan dengan kode $\mathrm{BCH}(31,16)$ dan dikodekan per 26 bit masukan dengan kode $\mathrm{BCH}(31,26)$. Untuk kode $\operatorname{BCH}(31,16)$ terdapat 2600 frame dan kode $\operatorname{BCH}(31,26)$ terdapat 1600 frame.

Tabel 1. Properties comm. BCHEncoder.

\begin{tabular}{|c|c|}
\hline CodewordLength & $\begin{array}{l}\text { Panjang kata kode } \\
\text { dalam bit. Disimbolkan } \\
\text { dengan } n \text { yang diatur } \\
\text { 31. Bila tidak diatur } \\
\text { maka akan default } 15 .\end{array}$ \\
\hline MessageLength & $\begin{array}{l}\text { Panjang informasi } \\
\text { dalam bit. Disimbolkan } \\
\text { dengan } k \text { yang diatur } \\
16 \text { dan } 26 \text {. Bila tidak } \\
\text { diatur maka akan } \\
\text { default } 5 \text {. }\end{array}$ \\
\hline GeneratorPolynomial & $\begin{array}{l}\text { Polinomial generator. } \\
\text { Nilainya otomatis } \\
\text { menyesuaikan dengan } \\
n \text { dan } k \text { yang } \\
\text { digunakan. Defaultnya } \\
\text { menyesuaikan }(n, k)= \\
(15,5) .\end{array}$ \\
\hline PrimitivePolynomial & 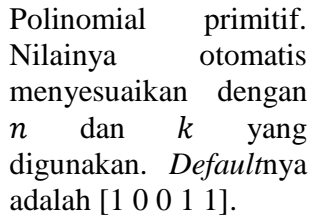 \\
\hline
\end{tabular}

Informasi yang telah dikodekan kemudian dimodulasi 32-FSK sebelum ditransmisikan.
Pada proses transmisi sinyal melewati kanal di mana dalam simulasi dilakukan untuk kanal AWGN saja, kanal AWGN ditambah Rayleigh dan AWGN ditambah Rician. Pada penerima, dilakukan demodulasi dan pendekodean untuk mendapatkan informasi asli. Untuk mengukur kinerja kode dilakukan perhitungan BER pada nilai SNR yang ditingkatkan dari 5 sampai 25 dB. Setiap subsistem dalam Gambar 1 tersebut disimulasikan dengan system object pada Matlab. Salah satu contoh properties system object ditunjukkan pada Tabel 1.

Berdasarkan Tabel 1, generator polinomial dan polinomial primitif pengkode $\mathrm{RS}$ dan $\mathrm{BCH}$ yang digunakan dalam simulasi dibangkitkan secara otomatis oleh system object Matlab berdasarkan nilai $n$ dan $k$ yang dimasukkan.

Untuk menyimulasikan pengiriman data dan pengaruh kanal pada kinerja BER maka digunakan parameter simulasi sebagamana ditunjukkan pada Tabel 2.

Tabel 2. Parameter Simulasi

\begin{tabular}{|c|c|}
\hline Parameter & NIlai \\
\hline Jumlah data (bit) & 832000 \\
\hline Kecepatan kendaraan $(\mathrm{km} / \mathrm{jam})$ & 60 \\
\hline Frekuensi pembawa $(\mathrm{MHz})$ & 1800 \\
\hline Periode simbol (detik) & $5 \times 10^{-7}$ \\
\hline Parameter K pada kanal Rician & 40 \\
\hline
\end{tabular}

\section{HASIL DAN PEMBAHASAN}

Gambar 2 menunjukkan hasil simulasi sistem dengan dan tanpa kode pengoreksi error pada kanal AWGN Sistem dengan kode koreksi mampu menurunkan nilai BER dari sistem tanpa kode koreksi. Dapat dilihat bahwa kinerja kode RS $(31,16)$ dalam menurunkan BER lebih baik daripada kode RS $(31,26)$. Demikian juga dengan kode $\mathrm{BCH}(31,16)$ yang memiliki kinerja BER lebih baik daripada kode $\operatorname{BCH}(31,26)$ Hal ini dikarenakan nilai $n$ dikurangi $k(n-k)$ yang menentukan jumlah error yang dapat diperbaiki, lebih besar pada kode dengan $(n, k)=(31,16)$ daripada $(n, k)=(31,26)$. Sementara itu jika kode RS dengan kode $\mathrm{BCH}$ diperbandingkan, hasilnya menunjukkan bahwa kode $\mathrm{BCH}$ pada SNR yang rendah memiliki kinerja BER yang lebih baik daripada kode RS. Akan tetapi dengan pertambahan SNR, grafik kode RS semakin 
curam dan lebih cepat menurunkan nilai BER sampai mendekati nol dibandingkan dengan kode $\mathrm{BCH}$, sehingga kinerja kedua kode menjadi serupa. Dari hasil simulasi, pada SNR $17 \mathrm{~dB}$, nilai BER kode RS $(31,16)$ dan kode $\mathrm{BCH}$ $(31,16)$ sama-sama mendekati nol. Sedangkan nilai BER kode RS $(31,26)$ dan $\mathrm{BCH}(31,26)$ mendekati sama pada SNR di atas $18 \mathrm{~dB}$.

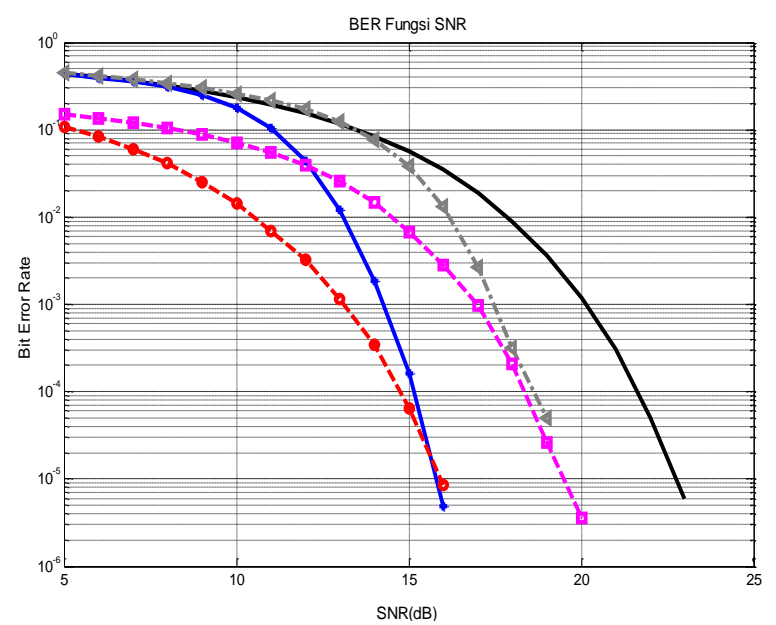

\begin{tabular}{|l}
\hline Nilai BER Sistem Tanpa Kode Pengoreksi \\
Nilai BER Sistem dengan $\mathrm{RS}(31,16)$ \\
- Nilai BER Sistem dengan $\mathrm{BCH}(31,16)$ \\
- Nilai BER Sistem dengan $\mathrm{RS}(31,26)$ \\
- Nilai BER Sistem dengan $\mathrm{BCH}(31,26)$
\end{tabular}

Gambar 2. Hasil penelitian sistem dengan modulasi 32-FSK pada kanal AWGN

Gambar 3 menunjukkan hasil simulasi sistem tanpa kode pengoreksi error, sistem dengan kode koreksi error $\mathrm{BCH}$ dan RS pada kanal Rician. Dapat ditunjukkan bahwa nilai BER kode BCH lebih baik pada saat SNR rendah, tetapi dengan peningkatan nilai SNR, penurunan nilai BER kode RS $(31,16)$ menjadi lebih cepat dan mendekati nilai BER kode BCH $(31,16)$. Hal yang sama terjadi jika penurunan nilai BER kode $\mathrm{RS}(31,26)$ dibandingkan dengan kode $\mathrm{BCH}$ $(31,26)$. Hasil simulasi juga menunjukkan nilai BER RS $(31,16)$ dan BCH $(31,16)$ mencapai nol pada SNR sebesar $19 \mathrm{~dB}$. Seperti halnya pada kanal AWGN, hasil simulasi pada kanal Rician ini juga menunjukkan bahwa kode $\mathrm{BCH}$ maupun RS dengan $(n, k)=(31,16)$ memberikan hasil lebih baik dalam menurunkan BER dibandingkan dengan $(n, k)=(31,26)$.
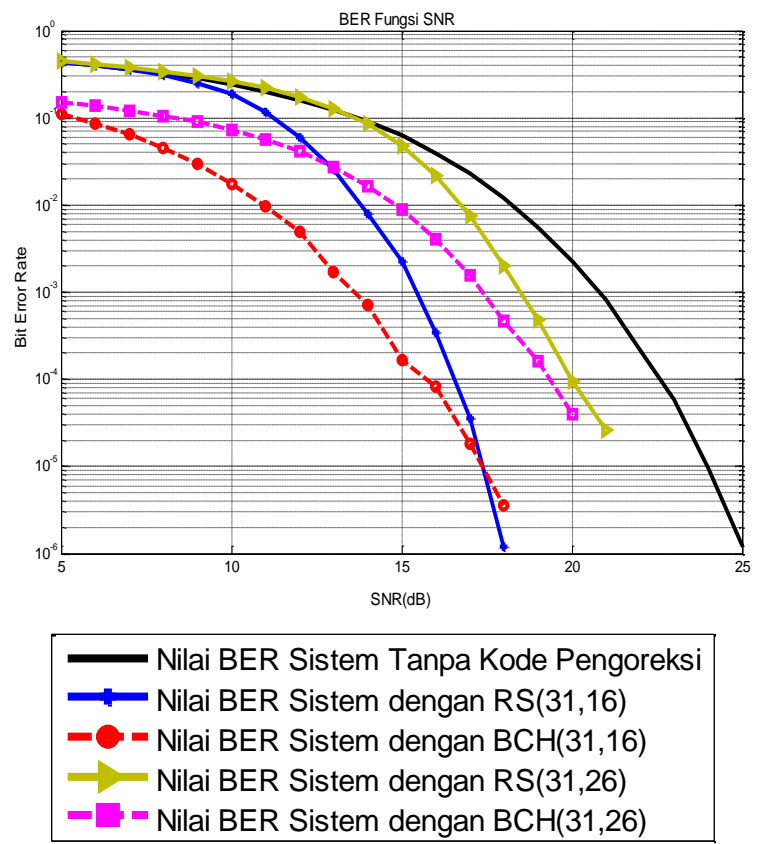

Gambar 3. Hasil penelitian sistem dengan modulasi 32-FSK pada kanal fading Rician

Simulasi sistem komunikasi yang dilewatkan pada kanal Rayleigh tanpa kode koreksi error dan dengan kode pengoreksi error $\mathrm{BCH}$ dan $\mathrm{RS}$ ditunjukkan pada Gambar 4.

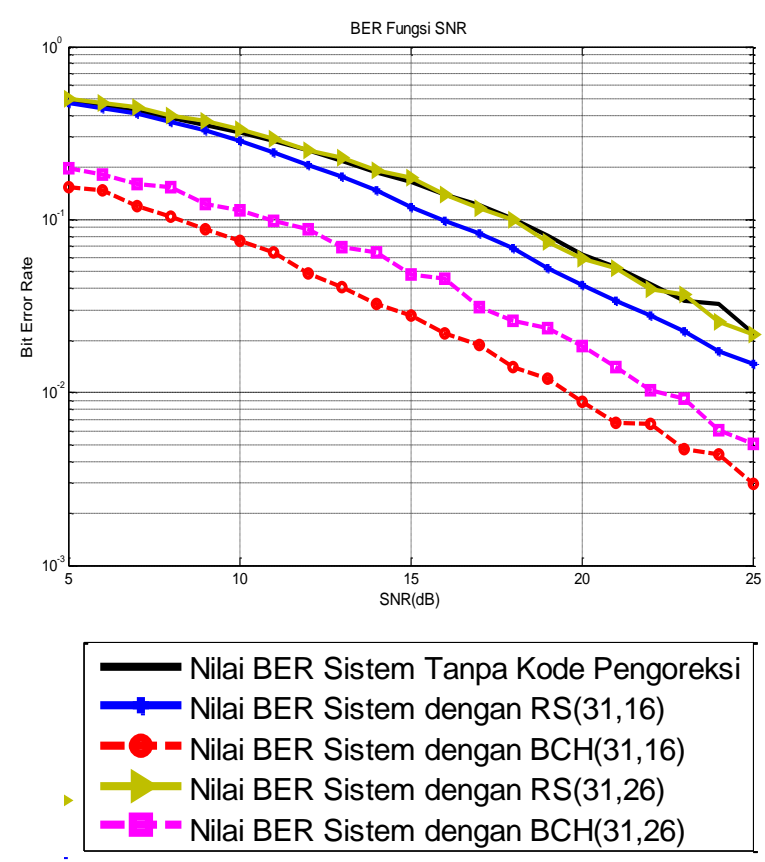

Gambar 4. Hasil penelitian sistem dengan modulasi 32-FSK pada kanal fading Rayleigh 
Dari grafik dapat diamati bahwa kinerja BER kode-kode koreksi error yang paling baik menurunkan nilai BER adalah kode $\mathrm{BCH}(31,16)$, diikuti oleh $\mathrm{BCH}(31,26)$, kode RS $(31,16)$, dan RS $(31,26)$. Dengan demikian pada kanal Rayleigh, kinerja BER kode BCH lebih baik daripada kode RS. Hasil simulasi menunjukkan diperlukan SNR yang lebih tinggi lagi untuk menurunkan BER menjadi mendekati nol. Hasil simulasi ini juga menunjukkan bahwa kode $\mathrm{BCH}$ maupun RS dengan $(n, k)=(31,16)$ memberikan hasil lebih baik dalam menurunkan BER dibandingkan dengan $(n, k)=(31,26)$.

Dari ketiga kanal yang disimulasikan untuk kedua kode pengoreksi error diperoleh bahwa nilai BER paling rendah atau kinerja BER yang paling baik adalah pada kanal AWGN dan yang terburuk adalah pada kanal Rayleigh. Kinerja BER pada kanal Rician berada di tengahtengahnya. Kanal AWGN merupakan pemodelan kanal ideal, sehingga terjadinya error akan segera dapat dikoreksi oleh kode kode koreksi error. Sementara itu kanal Rician memodelkan kondisi kanal fisik radio line of sight, di mana di antara pengirim dan penerima tidak terdapat penghalang. Namun demikian kanal radio ini bersifat meredam sehingga meningkatkan peluang terjadinya error lebih besar daripada kanal AWGN. Kanal fading Rayleigh merupakan kanal fisik/kanal radio yang bersifat non line of sight di mana antara pengirim dan penerima terdapat penghalang dan terjadi pantulan serta hamburan pada sinyal yang dikirimkan. Kanal fading Rayleigh juga memperhitungkan efek Doppler akibat adanya pergerakan pengguna atau objek pemantul. Hal ini menyebabkan informasi yang dikirimkan rentan mengalami burst error sehingga nilai BER meningkat pada saat diterima dibandingkan dengan kanal AWGN dan Rician.

Sistem dengan kode $R S(31,16)$ dan kode $\mathrm{BCH}(31,16)$ dapat menurunkan nilai BER yang lebih baik dibandingkan sistem dengan kode $R S(31,26)$ dan kode $\operatorname{BCH}(31,26)$. Hal ini disebabkan oleh kemampuan mengoreksi error dari kode $\operatorname{RS}(31,16)$ sebesar $t=\frac{31-16}{2}=7,5 \approx$ 7 simbol lebih besar dibandingkan kemampuan mengoreksi kode $\operatorname{RS}(31,26)$ sebesar $t=$ $\frac{31-26}{2}=2,5 \approx 2$ simbol . Untuk kode $\mathrm{BCH}(31,16)$ dengan kode $\mathrm{BCH}(31,26)$, kemampuan mengoreksi error kode $\mathrm{BCH}(31,16)$ sebesar $t=\frac{31-16}{5}=3$ bit lebih besar dibandingkan kode $\operatorname{RS}(31,26)$ sebesar $t=$ $\frac{31-26}{5}=1$ bit.

Dari nilai-nilai kemampuan mengoreksi error di atas diketahui kode RS $(31,16)$ dapat mengoreksi sistem yang mengalami BER sebesar atau di bawah $\frac{7}{31}=0,2258=22,58 \%$ menjadi sistem dengan nilai BER sebesar 0 . Untuk kode RS $(31,26)$, dapat mengoreksi sistem yang mengalami BER sebesar atau di bawah $\frac{2}{31}=0,0645=6,45 \%$ menjadi sistem dengan nilai BER sebesar 0. Untuk kode $\mathrm{BCH}$ $(31,16)$, dapat mengoreksi sistem yang mengalami BER sebesar atau di bawah $\frac{3}{31}=$ $0,0968=9,68 \%$ menjadi sistem dengan nilai BER sebesar 0. Untuk kode $\mathrm{BCH}(31,26)$, dapat mengoreksi sistem yang mengalami BER sebesar atau di bawah $\frac{1}{31}=0,0323=3,23 \%$ menjadi sistem dengan nilai BER sebesar 0 .

Dapat diamati kode pengoreksi error seharusnya dapat mengoreksi error dimanapun posisinya sehingga sistem bebas dari error dengan syarat BER pada sistem sama atau lebih kecil dari kemampuan mengoreksi kode pengoreksi error. Tetapi pada penelitian, misal pada sistem dengan modulasi 32-FSK yang menggunakan kanal AWGN tanpa kode pengoreksi dengan SNR sebesar $11 d B$ dicapai nilai BER sebesar 19,6505\%. Dengan SNR yang sama, sistem dengan modulasi 32-FSK yang menggunakan kanal AWGN dan kode pengoreksi RS $(31,16)$ memiliki BER sebesar $10,3584 \%$. Seharusnya kode RS $(31,16)$ dapat mengoreksi hingga $B E R$ yang didapat $0 \%$. Hal ini disebabkan oleh letak error menumpuk pada suatu frame sehingga pada frame itu banyaknya error melebihi kemampuan mengoreksi dari kode RS $(31,16)$. Sehingga ada frame-frame yang tidak bisa dikoreksi bebas dari error, yang berakibat BER yang didapat tidak $0 \%$.

Keunggulan sistem dengan kode RS $(31,16)$ adalah seiring dengan penambahan nilai SNR, dalam penelitian terlihat penurunan nilai BER yang lebih curam bila dibandingkan sistem dengan kode $\mathrm{BCH}(31,16)$. Hal ini disebabkan oleh kemampuan mengoreksi kode RS lebih besar daripada kode $\mathrm{BCH}$.

Sedangkan keunggulan sistem dengan kode BCH $(31,16)$ adalah saat SNR bernilai kecil, sistem dengan kode $\mathrm{BCH}$ memiliki BER lebih 
baik daripada sistem dengan kode RS. Hal ini disebabkan oleh proses pengoreksian masingmasing kode pengoreksi error. Kode $\mathrm{BCH}$ mengoreksi error dengan besar bit 0 atau 1 sedangkan kode RS mengoreksi error dengan besar symbol 0 sampai $n$, misal kode RS $(31,16)$ mengoreksi error dengan besar simbol $0,1,2,3, \ldots, 31$. Saat kode pengoreksi error dapat mengoreksi error dengan benar maka tidak akan terjadi masalah, tetapi bila gagal dalam mengoreksi error, kode $\mathrm{BCH}$ mempunyai peluang yang lebih besar mendapat keluaran yang sama dengan masukan dibandingkan kode RS.

\section{KESIMPULAN}

Berdasarkan hasil penelitian yang telah dilakukan, maka dapat disimpulkan beberapa hal berikut ini. Kode RS dan kode BCH dengan selisih (n-k) yang lebih besar mampu menurunkan nilai BER lebih baik. Kode RS dan kode $\mathrm{BCH}$ dengan panjang kata kode dan panjang informasi $(n, k)$ yang sama masingmasing memiliki keunggulan. Keunggulan sistem dengan kode RS adalah seiring dengan penambahan nilai SNR, terutama dalam penelitian pada kanal AWGN dan Rician, terlihat penurunan nilai BER yang lebih curam bila dibandingkan sistem dengan kode $\mathrm{BCH}$. Hal ini disebabkan oleh kemampuan mengoreksi kode RS lebih besar daripada kode $\mathrm{BCH}$. Keunggulan sistem dengan kode $\mathrm{BCH}$ adalah saat SNR bernilai kecil, sistem dengan kode BCH memiliki BER lebih baik daripada sistem dengan kode RS. Hal ini disebabkan oleh proses pengoreksian masing-masing kode pengoreksi error. Pada setiap kode pengoreksi kanal Rayleigh menunjukkan nilai BER paling buruk dibandingkan kanal Rician dan AWGN. Pada kanal Rayleigh kinerja kode $\mathrm{BCH}$ lebih baik dibandingkan kode RS pada rentang nilai SNR 0-25 dB.

\section{DAFTAR PUSTAKA}

[1] Haykin, S., Communication Systems 4th $e d .$, John Wiley and Sons, Inc. (2001).

[2] Mahajan, S. \& Singh, G. BER Performance of Reed-Solomon Code Using M-ary FSK Modulation in AWGN Channel, International Journal of
Advances in Science and Technology, Vol. 3, No.1, 7-15 (2011)

[3] Shanmugasundaram, T.A., Nachiappa, A., An Insight into BER Performance of ReedSolomon coded M-FSK under AWGN, Rayleigh and Rician Fading Channels, International Journal of Advanced Research in Electrical, Electronics and Instrumentation Engineering Vol. 2, Issue 4, 1488-1492 (April 2013)

[4] Lone, F. R., Puri, A., Kumar, S., Performance Comparison of Reed Solomon Code and BCH Code over Rayleigh Fading Channel, International Journal of Computer Application, vol. 71, no. 20, 23-26 (2013)

[5] Sklar, B., Digital Communications: Fundamentals and Applications, 2nd Edition, (2001)

[6] Lin, S., Costello, D. J. Jr., Error Control Coding: Fundamentals and Applications, Pretince-Hall Inc. Englewood Cliffs, New Jersey (1983)

\section{Biodata Penulis}

Eva Yovita Dwi Utami, memperoleh gelar Sarjana Teknik dari jurusan Teknik Elektro Sekolah Tinggi Teknologi Telkom, Bandung dan gelar Magister Teknik dari Departemen Teknik Elektro Universitas Indonesia. Saat ini sebagai staf pengajar program studi Teknik Elektro Universitas Kristen Satya Wacana, Salatiga dengan minat penelitian dalam bidang Komunikasi Nirkabel dan Antena dan Propagasi.

Liang Arta Saelau, memperoleh gelar Sarjana Teknik dari program studi Teknik Elektro Universitas Kristen Satya Wacana, Salatiga.

Andreas A. Febrianto, memperoleh gelar Sarjana Teknik dari jurusan Teknik Elektro Universitas Kristen Satya Wacana, dan gelar Magister Teknik dari Departemen Teknik Elektro Universitas Gajah Mada. Saat ini sebagai staf pengajar program studi Teknik Elektro Universitas Kristen Satya Wacana, Salatiga dengan minat penelitian dalam bidang Pengolahan Sinyal Informasi. 